\title{
Um olhar sobre a didática de Geografia em Portugal
}

\author{
Eunice Isaias da Silva* \\ Lana de Souza Cavalcanti** \\ Sérgio Claudino Nunes***
}

\begin{abstract}
Resumo
Este artigo é um relato, que resultou de um estágio realizado, no departamento de Geografia da Universidade de Lisboa, no período de 16 de maio a 20 de junho de 2009 . O trabalho consistiu em uma investigação bibliográfica sobre produçôes científicas a respeito de didática de Geografia em Portugal, com a finalidade de fornecer mais subsídios à produção da tese de doutorado intitulada "A linguagem dos quadrinhos na mediação do ensino de Geografia: charges e tiras de quadrinhos no estudo de cidade". Evidenciou-se que este tema é um debate que ainda ocupa um lugar restrito na academia portuguesa, mas é uma preocupação que se intensificou entre os professores e pesquisadores da Geografia escolar deste País, nos últimos anos. Isto pode ser constatado nos artigos publicados em obras científicas especializadas. Verificou-se, ainda, que as questôes que se enfrentam nas açóes envolvidas no ensino de Geografia em Portugal e as respectivas soluçóes propostas são, em síntese, muito semelhantes às da educação geográfica brasileira. $\mathrm{O}$ estágio foi uma etapa de grande importância na formação acadêmica, com várias atividades que possibilitaram um proveitoso conhecimento do ensino e teoria geográfica portuguesa. Percebeu-se, sobretudo, que tanto o Brasil como Portugal poderão trocar valiosas experiências com os possíveis intercâmbios científicos de Geografia, se porventura interessarem em consolidá-los.

Palavras-chave: estágio em Portugal, ensino de Geografia, didática de Geografia.
\end{abstract}

A look at the teaching of Geography in Portugal

Abstract

This article is a report on a placement in the Department of Geography at the University of Lisbon, from May 16 to June 20, 2009. The work involved a literature search of the scientific production on the teaching of Geography in Portugal, in order to provide support material

* Professora de Geografia do Cepae/UFG. Doutoranda em Geografia do Instituto de Estudos Sócio Ambientais (Iesa/UFG). E-mail: euniceisaias@gmail.com

** Professora do curso de Geografia do Iesa/UFG. E-mail: 1s.cavalcanti@uol.com.br

*** Professor do curso de Geografia da Universidade de Lisboa - PT. E-mail: sergio@campus.ul.pt 
for the writing of a doctoral thesis entitled, "The language of comic strips in mediating the teaching of Geography: using political cartoons and comic strips to study a city". It was evident that this theme still occupies little space in Portuguese academia but it is a concern being felt more and more acutely by researchers and teachers of Geography there in recent years. This can be seen from articles published in specialized scientific journals. It was also seen that the issues confronted in the teaching of Geography in Portugal and their respective solutions are, in short, very similar to those involved in the Brazilian teaching of Geography. This placement of significant importance in academic formation involved various activities that provided opportunities for enhancing one's knowledge of teaching and Portuguese geographical theory. Above all, it was seen that both Brazil and Portugal could exchange valuable experiences with the possibility of scientific exchanges in Geography, if there was interest in the consolidation of such.

Keywords: placement in Portugal, teaching Geography, the didactics of Geography

\section{Consideraçóes iniciais}

"Eu não quero ter o Tejo me escorrendo das mãos..."

Zeca Baleiro, Bandeira.

A realização de um estágio na Universidade de Lisboa teve como objetivo principal analisar e avaliar as produções bibliográficas sobre a didática de Geografia em Portugal. A intenção é que esta experiência contribua para a elaboraçáo da tese de doutoramento que faz uma reflexáo sobre a metodologia do ensino de Geografia, com enfoque no uso de quadrinhos (conhecido como banda desenhada ou $\mathrm{BD}$, em Portugal) para mediar o processo ensino-aprendizagem de Geografia da cidade. A investigação bibliográfica ocorreu no período de 18 de maio a 09 de junho de 2009, na biblioteca da Faculdade de Letras, unidade na qual também se localiza o departamento de Geografia da Universidade de Lisboa.

Neste texto, pretende-se apresentar, essencialmente, o resultado da pesquisa bibliográfica: na primeira seção, as principais discussões sobre didática de Geografia em Portugal; na segunda, a proposiçáo do emprego de imagens no ensino de Geografia em Portugal; em seguida, abordamse as propostas para o ensino de cidade na Geografia portuguesa e, finalmente, são relatadas várias sugestôes e experiências didáticas para o ensino de Geografia, relacionadas a outras temáticas geográficas. Certamente este trabalho poderá contribuir para o debate sobre metodologia da Geografia escolar. 


\section{Notas sobre a didática de Geografia em Portugal}

Inicialmente, para possibilitar melhor compreensão, a estrutura do ensino de Geografia em Portugal foi resumida no quadro a seguir:

Quadro 1: Estrutura do ensino de Geografia em Portugal.

\begin{tabular}{|l|l|l|l|}
\hline Grau de ensino & Ciclo & Ano & Formaçáo geográfica \\
\hline Ensino básico & \multirow{2}{*}{$1^{\circ}$} & $1^{\circ}$ & Estudo do meio \\
& & $2^{\circ}$ & \\
\cline { 2 - 3 } & $3^{\circ}$ & \\
\cline { 2 - 3 } & $4^{\circ}$ & \\
\cline { 2 - 3 } & $2^{\circ}$ & $5^{\circ}$ & História e Geografia de Portugal \\
\cline { 2 - 3 } & $6^{\circ}$ & \\
\hline \multirow{3}{*}{ Ensino secundário } & $7^{\circ}$ & Geografia \\
& & $8^{\circ}$ & (obrigatória) \\
\cline { 3 - 4 } & $9^{\circ}$ & \\
\hline & $10^{\circ}$ & Geografia \\
& $11^{\circ}$ & (opcional) \\
\hline & $12^{\circ}$ & \\
\hline
\end{tabular}

Fonte: Elaborado por Sérgio Claudino Nunes.

Em muitas publicaçóes portuguesas especializadas que abordam a didática do ensino de Geografia, vários autores criticam o ensino tradicional e insistem na necessidade de açóes para renovar o ensino da disciplina nos períodos escolares em que ela é estudada, conforme demonstra o Quadro 1 (Cachinho; Reis, 1991; Esteves, 2006; Nunes, 2000, 2006; Reis, 2002, 2004). Há uma crítica generalizada à memorização, que forma alunos passivos, além da proposição de superar a Geografia descritiva, dispersa e conceitualmente vazia. Eles ressaltam o propósito de formar alunos ativos, capazes de pensar, criar e realizar tarefas sob a orientaçáo do professor.

Percebe-se que, notadamente nos últimos anos, a Geografia portuguesa preocupou-se em construir uma educação para a cidadania, o que significa considerar o ensino-aprendizagem de Geografia como um conjunto de saberes associados à formaçáo cidadá. Isso sob a prerrogativa de que o aluno é um ser social e necessita ter na educação uma atividade contínua cujas metas sejam satisfazê-lo e integrá-lo à vida. Neste processo, deve-se, 
com base nos saberes prévios dos alunos, buscar desenvolver sua capacidade de refletir criticamente sobre o mundo atual. Desse modo, consolida-se o exercício da ética e da responsabilidade social por meio da valorização da identidade cultural.

O conceito de educação geográfica, que define bem esse propósito, pode ser exemplificado na seguinte consideração de Alberto:

Os alunos têm que compreender a importância do Espaço na sua vida quotidiana e na vida da sociedade; ou seja, "saber pensar e utilizar o espaço". Para isso é necessário que o aluno domine os conceitos básicos, para adquirir as capacidades e o raciocínio geográfico que lhe permitam compreender e enfrentar situaçóes novas, mesmo a diferentes escalas. Tal como se espera que os alunos aprendam a ler e a escrever, também se espera que eles aprendam a utilizar o território, duma forma eficaz e criar o hábito de analisar os problemas, numa perspectiva espacial, de modo a que possam compreender melhor o meio onde vivem. (2001, p. 75, grifo nosso).

A autora argumenta que o aluno deve compreender satisfatoriamente o que ocorre no mundo, de uma forma geral, e em seu meio, de forma particular - ou seja, conhecer o local e o global e suas articulaçóes.

Conforme Reis (2002, p. 96), "a Geografia é a ciência do espaço e do lugar" e a paisagem é um conceito central desse conhecimento. Com esta perspectiva, Mendes e Lopes (2004, p. 24) destacam que: "Os conceitos são considerados 'produtos científicos' essenciais para o ensino" [grifo dos autores]. Compreendem também que a educação deve ser centrada em conceitos geográficos e que a aprendizagem consiste em saber aplicar e transportar o conceito para a realidade de cada estudante. Portanto, deve-se educar geograficamente para a resolução dos problemas cotidianos, para o exercício crítico e a consolidaçáo da cidadania. Desse modo, solidifica-se o "pensar geográfico" para atuar no meio em que se vive.

Para se obter êxito nessa caminhada, esses investigadores confirmam a necessidade de colocar em prática um currículo menos rígido e uniforme, em que a relaçáo ensino-aprendizagem se fundamente na problematização dos temas relacionados ao conhecimento geográfico. Para tanto, o professor deverá organizar a sua proposta de trabalho a partir das ideias prévias dos alunos, selecionando os problemas reais e significativos para eles, de modo que resulte em uma Geografia viva e inserida nas questóes sociais. 
Mediante o pressuposto de que aprender e ensinar consistem em investigar, os teóricos defendem que os conceitos não devem ser apresentados como acabados, antes devem constituir processos contínuos de construção com base na investigação escolar. Neste sentido, Cachinho e Reis (1991, p. 439) situam o conhecimento como operativo e afirmam: "O aluno constrói o seu conhecimento a partir das suas experiências e dos conceitos que já possui". Esses autores consideram que, na investigação escolar, um princípio fundamental é possibilitar aprendizagens significativas e globalizantes nas quais o professor seja mediador e investigador; sendo assim, ele deve afastar-se do papel tradicional de estimular e explicar lições. O ensino de Geografia deve problematizar o real e oferecer perspectivas de intervenção no cotidiano de cada um. Neste caso, o trabalho precisa se adequar à diversidade de públicos e contextos a fim de tornar os alunos atores e autores de suas aquisiçóes geográficas.

Observa-se, portanto, o reconhecimento de que, para superar a Geografia enciclopédica, é necessário empreender mudanças nos papéis desempenhados por alunos e professores. Desta forma, tem-se o professor como estimulador da reconstrução do saber do aluno, com o propósito de desenvolver atitudes e competências para o enfrentamento crítico e criativo dos desafios do mundo em que ele vive. Essa postura se constatou em muitas publicações científicas da Geografia portuguesa, nas quais se evidenciam uma grande preocupação com o papel da Geografia na educação ambiental e a proposição de novas atitudes e atividades docentes na Geografia escolar.

Destaca-se, nesse aspecto, a revista Apogeo, uma publicação da Associação dos Professores de Geografia - Portugal (Aprofgeo). Desde o ano de 1988, esse periódico divulga artigos que tratam da interdisciplinaridade e multidisciplinaridade, do construtivismo piagetiano, da importância da cartografia referente à análise de manuais escolares, além de apresentar produçóes que discutem sobre a geografia de Portugal, as migraçóes, o etnocentrismo e a necessidade de um currículo alternativo para a Geografia no ensino especial. Tem publicado, ainda, vários relatos sobre experiências de atividades didático-pedagógicas, como: trabalho de campo, jogos de simulação, uso de informática, trabalho com poesia, música, cartuns, fotos, mapas, gráficos, dentre outras propostas. Além disso, a revista disponibiliza recursos didático-pedagógicos sobre temáticas geográficas, tais como: cartuns, mapas, tabelas, gráficos, textos, principalmente sobre a geografia de 
Portugal e do continente europeu. A partir do número 27/28, de outubro de 2004, a revista Apogeo a apresentar sempre um cartum do geógrafo Luís Afonso com mensagem pertinente ao conhecimento geográfico, que permite reflexóes e leituras geográficas. No número 35 (2008), por exemplo, foi publicado um cartum (Figura 1) que motiva o debate sobre a questão ambiental na Terra.

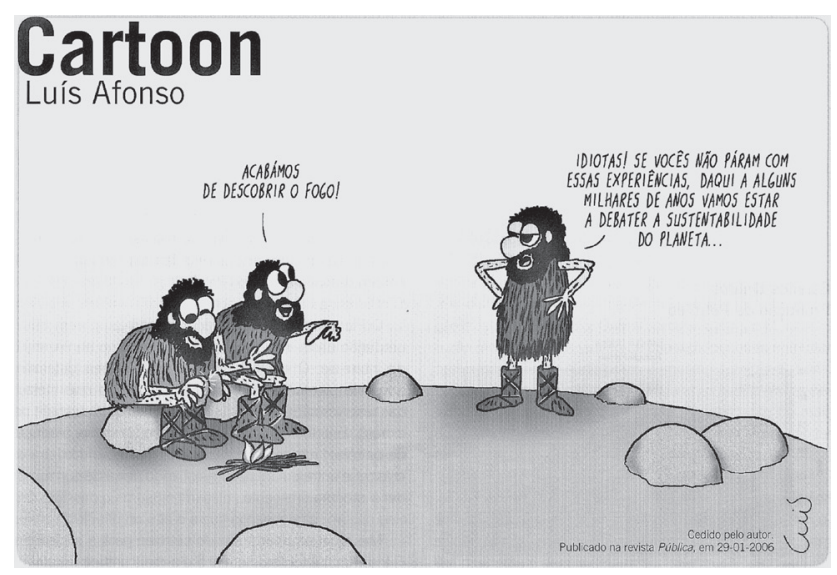

Figura 1- Cartum de Luís Afonso

Fonte: Apogeo - revista da Associação de Professores, Lisboa, n. 35, p. 3, dez. 2008.

A seguir, algumas notas sobre possibilidades de uso de imagens no ensino de Geografia.

\section{Emprego de imagens na Geografia escolar portuguesa}

Os artigos relativos ao uso de imagens no ensino de Geografia são numericamente inferiores aos direcionados à educação ambiental nas publicaçóes sobre Geografia escolar. Em sua grande maioria, relacionam-se à utilização de mapas geográficos, contudo enfatizam a importância da imagem na sociedade atual.

Desta perspectiva, Alegria (2005) considera que a imagem é uma representação do real, portanto sua análise exige conhecimento e interpretação, e reconhece que ainda é escasso o conhecimento referente à leitura de imagens. Argumenta que a completa compreensão de uma imagem envolve 
os aspectos da trilogia autor-obra-público, por conseguinte deve-se estudar a obra, perceber as intençôes do autor e sua recepção pelos leitores (público). Considera a imagem como uma linguagem que possibilita várias interpretações. $\mathrm{O}$ mundo está sobrecarregado de imagens que podem constituir uma linguagem universal, na medida em que é simbólica, como os mapas hipsométricos cuja compreensão é possível em qualquer parte do mundo. Alegria (2001, p. 351) explica: "A imagem tem cada vez mais presença e importância na sociedade contemporânea" e, para algumas pessoas, ela chega a ser mais importante do que a própria realidade.

A capacidade da leitura de imagens é adquirida ou aperfeiçoada pela aprendizagem, como se aprende a linguagem verbal. Assim, ler imagens consiste em refletir sobre a mensagem por elas transmitida ou sugerida e verbalizar a compreensão alcançada.

Como uma imagem não é uma reprodução fiel da realidade, Alegria (2001) ressalta que ela dá margem a várias leituras. E acrescenta ainda que, ao considerar a possibilidade de várias interpretaçóes, o professor deve ser cuidadoso para não impor a sua própria leitura. Seu papel deve ser o de orientar a análise mais pertinente de acordo com os objetivos do conteúdo estudado, sem descartar as outras representaçóes possíveis.

De acordo com a autora, a linguagem imagética e a linguagem verbal se completam. No entanto, a linguagem textual costuma ser mais valorizada no ensino e na sociedade de uma forma geral, exceto em relação às fotografias, que às vezes se aproximam tanto do real que acabam sendo confundidas com ele. Salienta, porém, que a imagem é uma forma de descrever a realidade e que, na sua análise, constroem-se as interpretaçóes.

Alegria explica também que um título, ou uma legenda, pode contribuir na leitura da imagem ou até mesmo influenciar e manipular a ótica de quem a lê. Por outro lado, a ausência de um texto muitas vezes dificulta a sua interpretação. Afirma que a escola pode e deve contribuir para a leitura de imagens, considerando-a como um recurso didático-pedagógico. No ensino pela imagem, a motivaçáo de sua análise deve ser mais criteriosa para que se alcance uma leitura reflexiva e crítica.

Nesse sentido, a leitura da imagem deve fazer parte da cultura geográfica. Isso significa analisá-la em seus aspectos objetivos e subjetivos. Inicia-se pelo nível instintivo, que é a leitura instantânea, superficial, chegando, em seguida, ao nível descritivo, com a análise de seus elementos constitutivos 
até a interpretação de seu conteúdo simbólico de uma forma mais aprofundada. Tal postura poderá dar subsídios para responder ao desafio proposto por Patrício e André (1984, p. 258): "Por que é que as mais famosas 'tabletes' de chocolate se vendem normalmente enroladas em verdejantes paisagens suíças, embora cheirando naturalmente a cacau africano e do melhor?” Agora, sob o impacto desse questionamento, serão comentadas determinadas atividades e experiências com imagens no ensino de Geografia.

A investigadora Alegria (2006) relatou um trabalho realizado por ela com imagens de paisagens de Portugal e da Espanha bastante conhecidas, sem legendas, no qual alunos universitários de ambos os países deveriam identificar os lugares. O objetivo era verificar se esses alunos reconheceriam as paisagens representativas desses dois países. A conclusão a que chegou é que havia, entre os alunos, um determinado grau de desconhecimento de paisagens bastante representativas de Portugal ou da Espanha quando as imagens visualizadas não eram de seu país.

Alegria (2005) comenta ainda a utilização de dois cartuns (sem texto escrito) sobre a questáo ambiental, um dos quais se referia a esta problemática com enfoque diferenciado entre os países do Norte e os do Sul. O objetivo da atividade foi identificar as diferentes leituras da mesma imagem (Figuras 2 e 3) realizadas por diferentes observadores. Ambos os cartuns foram utilizados em duas turmas distintas do ensino básico.

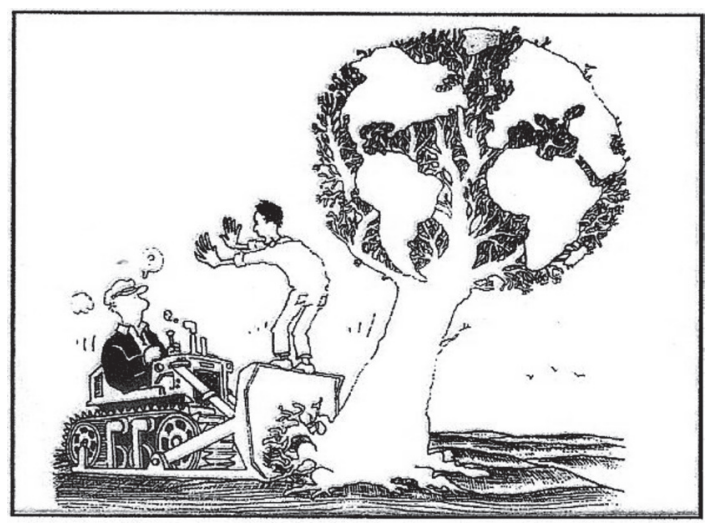

Figura 2 - Cartum 1

Fonte: Finisterra - Revista Portuguesa de Geografia, Lisboa, v. XL, n. 79, p. $186,2005$. 


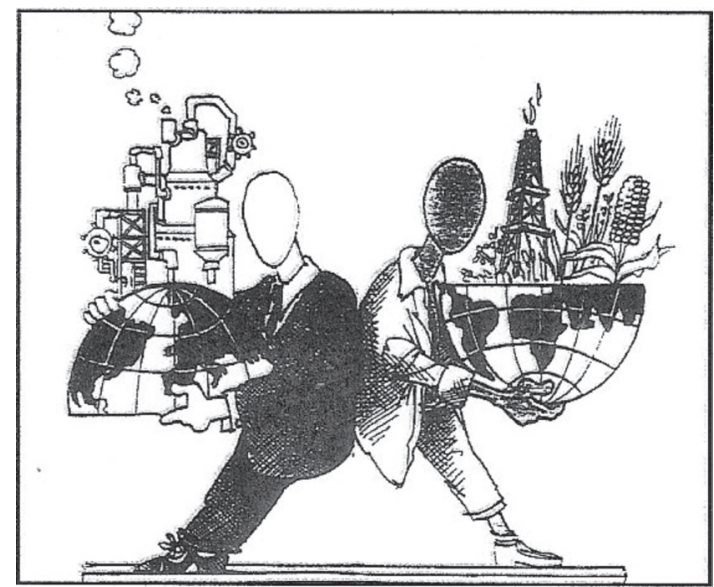

Figura 3 - Cartum 2

Fonte: Finisterra - Revista Portuguesa de Geografia, Lisboa, v. XL, n. 79, p. $186,2005$.

Assim, as mesmas imagens foram apresentadas para turmas de alunos do $9^{\circ}$ ano (13-14 anos de idade) e turmas de alunos do $11^{\circ}$ ano (faixa etária de 15-16 anos). A primeira foi entregue em uma aula e a segunda em outra aula, sem nenhum comentário sobre a mensagem delas. Sob a cópia de cada uma havia a orientação para que fosse interpretada e lhe fosse atribuído um título. Com essa atividade, pretendia-se verificar o nível de interpretação dos alunos, que foi classificado como muito bom, bom, razoável ou fraco. No final da investigação, a autora concluiu que os alunos em ano escolar mais avançado alcançaram uma melhor interpretação, com a construção de textos maiores, com maior clareza e com títulos mais coerentes. Entretanto, ela esclarece que os textos produzidos pelos alunos a respeito dessas duas figuras "[...] reconstituem apenas uma parte do que elas lhes sugeriram, porque a expressão linguística não consegue traduzir a globalidade de significados de uma imagem. Além disso, as dificuldades de expressão escrita são notórias, sobretudo nos alunos mais novos" (Alegria, 2005, p. 190).

Outros cartuns que foram utilizados no ensino básico e no secundário exemplificaram a percepção de seu discurso polissêmico. Também muitas propostas foram apresentadas para a leitura e interpretação de mapas, gráficos e outras imagens tidas como fundamentais para uma boa formação 
geográfica. Contudo, Alegria (2005) destacou que as investigações pedagógicas sobre leituras imagéticas ainda são pouco frequentes, notadamente em Geografia.

A próxima seção foi dedicada ao conteúdo de cidade no ensino de Geografia em Portugal.

\section{Sobre o ensino de cidade em Portugal}

Esteves (2006) avalia a forma como os programas e manuais didáticos de Geografia em Portugal indicam o ensino de cidade como conteúdo de Geografia escolar. Afirma inicialmente que o desafio para o ensino atual na sociedade urbana do mundo globalizado é formar cidadãos competentes não apenas em relação à memorização e à localização, mas, sobretudo, que os alunos devem aprender a questionar e a problematizar na leitura dos espaços próximo e distante.

A pesquisadora compreende que os manuais escolares passaram por grandes mudanças, porém ainda apresentam um modelo urbano já inexistente. De seu ponto de vista, eles configuram um apoio importante para o professor e é necessário investir na formação desse profissional para que ele possa contextualizar e atualizar os conteúdos referentes à cidade. A autora destaca: "Na medida em que vivemos num mundo cada vez mais urbanizado, torna-se particularmente importante estudar como se organizam as cidades, as transformaçóes que têm sofrido e de que forma condicionam os modos de vida" (Esteves, 2006, p. 212).

Conforme Esteves, no currículo de Portugal a cidade é abordada sob três eixos fundamentais: urbanização e ruralidade, modo de vida urbano e rural e estrutura das áreas urbanas. No entanto, lembra que essa abordagem não exclui a possibilidade de se estudar outros temas de interesse dos alunos ou do contexto escolar. E sugere que o estudo da cidade deve seguir o método investigativo com a seguinte compreensão: "Investigar a 'cidade' é [...] procurar respostas para as questôes que os alunos colocam sobre aquilo que observam; cabe ao professor organizar as situaçóes de aprendizagem, para ajudar os alunos a encontrar as respostas" (Esteves, 2006, p. 209).

Assim, para que o ensino de Geografia contribua para a cidadania participativa e consciente, os professores necessitam de uma formação contínua e coerente com o propósito de capacitar os alunos a ler a cidade em que 
vivem. De acordo com Esteves (2006), para se realizar essa leitura, existem vários caminhos, como alguns propostos em certas atividades como as do Quadro 2.

Quadro 2 - Sugestóes de experiências educativas sobre cidades

\begin{tabular}{|l|l|}
\hline Temas & Sugestão de experiências educativas \\
\hline Urbanização e ruralidade & $\begin{array}{l}\text { - Recolher informaçóes sobre os espaços urbanos e } \\
\text { rurais de Portugal e de outros países. } \\
\text { - Construir quadros para apresentação da informação } \\
\text { (gráficos, mapas, etc.). }\end{array}$ \\
\hline Estruturas de áreas urbanas & $\begin{array}{l}\text { - Realizar trabalho de campo na área envolvida. } \\
\text { - Analisar plantas de cidade. } \\
\text { - Realizar estudos que evidenciem as mudanças } \\
\text { funcionais que ocorrem no espaço urbano. }\end{array}$ \\
\hline Modos de vida urbano e rural & $\begin{array}{l}\text { - Recolher informações utilizando materiais } \\
\text { diversificados como livros, vídeos, etc., para } \\
\text { compreender as diferenças entre os modos de vida. }\end{array}$ \\
\hline
\end{tabular}

Fonte: Finisterra - Revista Portuguesa de Geografia, Lisboa, v. XL, n. 79, 2006. p. 209 (adaptado).

As professoras Câmara e Antunes (2008) recomendam a experiência "Cidade, espaço vivo e vivido". Nela, propóem a construção de uma cidade virtual simples por meio de um programa de computaçáo. $\mathrm{O}$ trabalho deve ser desenvolvido em grupos de alunos e finalizado com a produção do mapa da referida cidade, sua apresentação e discussão.

Outras sugestóes mais evidentes sobre o ensino de cidade foram: atualizar o conteúdo nos livros didáticos por meio de questôes investigativas sobre o uso do solo urbano da cidade em questão, utilizar imagens urbanas fixas ou em movimento e visitar determinados espaços da cidade como museus, praças, bairros. Reis (2004) indicou ainda uma pesquisa denominada "supermercado sem fronteira", que trata da origem do que se consome na cidade, além de uma atividade sobre imigração em determinados espaços urbanos.

As sugestóes de atividades com outros temas geográficos estão enumeradas na seção seguinte. 
Outras sugestóes e experiências didático-pedagógicas para o ensino de Geografia

Grande parte das sugestôes de atividades didáticas foi indicada para se trabalhar com os alunos em grupos (Cavaco, 1972; Reis, 2004; Fernandes; Mendes, 2006; Mendes; Lopes, 2004). A justificativa mais comum é que a criação em colaboração e o pensar em grupo estimulam o desenvolvimento de novos hábitos de respeito a si mesmo e ao outro.

Com esse entendimento, uma professora de Geografia (Lopes, 2007) sugeriu o jogo chamado detetive "Geo", que é semelhante à brincadeira caçatesouro. O grupo escolhe quem será o detetive "Geo", os demais alunos do grupo serão os seus auxiliares, que o ajudarão a seguir as pistas indicadas e a solucionar o problema proposto pelo professor dentro de um tempo estipulado. Alves (1970) recomendou o estudo de meteorologia com análise de dados de jornais e com o uso de termômetro na sala de aula. Ramalho (1998) relatou uma experiência com duas músicas, sendo a primeira $O$ resto do mundo, do brasileiro Gabriel, "O Pensador". A canção foi contextualizada para a realidade portuguesa. A outra música foi trazida pelos próprios alunos. Gouveia e Moreira (2001) propuseram uma lição de Geografia por meio da poesia.

Diversas outras propostas ou experiências foram relatadas em artigos científicos, principalmente nos vários números da revista Apogeo:

- envolver os pais dos alunos no convívio escolar compartilhando experiências, culturas diferentes, etc.;

- realizar um levantamento do uso do solo no centro de Portugal envolvendo várias escolas do ensino secundário;

- fazer uma pesquisa para avaliar o nível de comprometimento dos alunos em relação à questão ambiental;

- elaborar um Atlas Ambiental;

- desenvolver experiências com informática e vídeos em trabalhos de Geografia;

- promover jogos de simulação (julgamento, jornal falado, representação teatral) com grupos de alunos em diferentes temas;

- orientar a construção de dossiês pelos alunos sobre problemas ambientais, saúde, migraçáo e outros temas, por meio do uso de fotografias, desenhos, gráficos, mapas e textos; 
- estimular leituras literárias ou de livros paradidáticos;

- organizar exposição de artesanatos, fotos, revistas, jornais e alimentos de lugares específicos;

- utilizar folhetos turísticos, mapas rodoviários para trabalhar escalas geográficas, economia, aspectos sociais etc.

Entre as várias propostas de trabalho de campo ou visitas de estudo, um grande número ressalta a necessidade de planejamento e avaliação. Segundo os autores, a relevância desses trabalhos está, sobretudo, no fato de serem específicos de geógrafo e que, pela observação do contexto, tem-se acesso ao real.

Estas foram as principais contribuições evidenciadas nas publicaçóes nas quais se analisou a didática de Geografia em Portugal.

\section{Reflexóes finais}

Durante o transcurso desta pesquisa, verificou-se que, nos últimos anos, de modo semelhante ao que ocorre no Brasil, a preocupação com o ensino de Geografia em território português já é uma realidade. $\mathrm{O}$ fato está evidenciado nas discussóes teóricas registradas em periódicos especializados e em livros que resultaram de eventos científicos. É possível que este debate ainda não tenha o reconhecimento e o status percebidos em outras áreas da ciência geográfica, mas a polêmica já está instalada e poderá render bons frutos.

Outra percepção deste período de estágio na Universidade de Lisboa é que o diálogo entre a Geografia portuguesa e a brasileira ainda é muito débil. Os geógrafos do Brasil, com raras exceções, são pouco citados na produção geográfica de Portugal, e sabe-se que o mesmo ocorre na produção geográfica do Brasil em relação aos geógrafos de Portugal. E talvez o mais impressionante de tudo isso, conforme se constatou, é que os problemas enfrentados no ensino de Geografia em Portugal e as consequentes soluçóes propostas são muito semelhantes aos da Geografia escolar brasileira. Como exemplo, pode ser citada a preocupação em produzir uma Geografia escolar comprometida com a cidadania e com conteúdos significativos para o cotidiano dos estudantes. 
Com base nessas conclusóes, indaga-se: não seria interessante a intensificação da troca de experiências geográficas entre Portugal e Brasil, com base nas heranças históricas e na comunicação facilitada pela língua comum? Fica, portanto, o desafio de que se promovam outras atividades em colaboração mútua, uma vez que seriam de grande validade para a ciência geográfica dos dois países.

\section{Referências}

APOGEO - Revista da Associação de Professores. Lisboa, n. 27/28, mar./set. 2004.

APOGEO - Revista da Associação de Professores. Lisboa, n. 35, mar./set. 2008.

ALBERTO, A. O contributo da educação geográfica na educação ambiental. A Geografia no ensino ambiental. Estudos de Geografia Humana e Regional, Lisboa, n. 43, 2001.

ALEGRIA, M.F. Contributos para uma prática da leitura de imagens fixas. In: GAITE, M. J. M. (Org.). La formación geográfica de los ciudadanos en cambio de milénio. Madri: Asociación de geógrafos españoles, Associação de professores de Geografia de Portugal e Universidad complutense de Madrid, 2001. p. 351-359.

- Representações sobre a imagem na aprendizagem geográfica. Finisterra - Revista Portuguesa de Geografia, Lisboa, v. XL, n. 79, p. 177193, 2005.

- Paisagens desconhecidas de Portugal e Espanha. Respostas de alunos universitários de dois países. In: GAITE, M. J. M.; LORENZO, S. L. (Orgs). Cultura geográfica y educación ciudadana. Espanha: AGE/APG, 2006. p. 499-512.

ALVES, E. M. O ensino de Geografia ao nível secundário. Finisterra Revista Portuguesa de Geografia, Lisboa v. V, n. 10, p. 304-317, 1970. 
CACHINHO, H.; REIS, J. Geografia escolar (re)pensar e (re)agir. Finisterra - Revista Portuguesa de Geografia, Lisboa, v. XXVI, n. 52, p. 429-443, 1991.

CÂMARA, A. N.; ANTUNES, S. Cidade, espaço vivo e vivido. Apogeo Revista da Associação de Professores, Lisboa, n. 35, p. 40-52, dez. 2008.

CAVACO, M. H. O trabalho de grupo no ensino de geografia nos liceus. Finisterra - Revista Portuguesa de Geografia, Lisboa, v. VII, n. 14, p. 313323, 1972.

ESTEVES, M. H. F. Ensinar a "cidade" no ensino básico. Finisterra - Revista Portuguesa de Geografia, Lisboa, v. XLI, n. 81, p. 205-213, 2006.

FERNANDES, J.; MENDES, L. Seis chapéus para pensar a Geografia da população mundial. In: GAITE, M. J. M. e LORENZO, S. L. (Orgs). Cultura geográfica y educación ciudadana. Espanha: AGE/APG, 2006. p. 97110.

GOUVEIA, L.; MOREIRA, C. Lição de Geografia através de uma poesia. In: GAITE, M. J. M. (Org.). La formación geográfica de los ciudadanos en cambio de milénio. Madri: Asociación de geógrafos españoles, Associação de professores de Geografia de Portugal e Universidad complutense de Madrid, 2001. p. 539-551.

LOPES, A. Jogo “detective Geo”. Apogeo - Revista da Associação de Professores, Lisboa, n. 33, p. 44-45, dez. 2007.

MENDES, L.; LOPES, P. Imigração e acolhimento do outro; uma perspectiva sociocrítica da Geografia escolar. In: REIS, J. (Org.). Estudos de Geografia Humana e Regional - Boas práticas na educação geográfica. Lisboa, n. 46, p. 9-114, set. 2004.

NUNES, S. C. O ensino de Geografia em Portugal: uma perspectiva. Educação geográfica. Inforgeo, Lisboa, n. 15, p. 185-206, 2000.

. Geografia e educação ou o optismo possível. In: GAITE, M. J. M.; LORENZO, S. L. (Orgs.). Cultura geográfica y educación ciudadana. Espanha: AGE/APG, 2006. p. 217-226. 
PATRÍCIO, C.; ANDRÉ, I, M. As diferentes imagens da Geografia. Finisterra - Revista Portuguesa de Geografia, Lisboa, v. XIX, n. 38, p. 257 264, 1984.

RAMALHO, M. H. et al. A música ao serviço da educação geográfica. Inforgeo, Lisboa, n. 12/13, p. 643-650, dez. 1998.

REIS, J. (Org.) Boas práticas na educação geográfica. Estudos de Geografia Humana e Regional, Lisboa, n. 46, set. 2004.

REIS, J. Educação geográfica e cidadania: uma missão possível. In: CACHINHO, H. et al. Estudos de Geografia Humana e Regional - Olhares sobre o território e a espacialidade, Lisboa, n. 45, p. 95-106, dez. 2002.

Recebido em: 17 set. 2009

Aceito em: 27 jan. 2010 